OPEN ACCESS

Edited by:

Uday Kishore,

Brunel University London, UK

Reviewed by:

Uttara SenGupta

Northwick Park Institute for Medical

Research, UK

Kushagra Bansal,

Harvard Medical School, USA

${ }^{*}$ Correspondence:

Li Sun

Isun@qdio.ac.cn

Specialty section: This article was submitted to

Molecular Innate Immunity,

a section of the journal

Frontiers in Immunology

Received: 02 December 2016 Accepted: 28 February 2017

Published: 22 March 2017

Citation:

Zhao M-I, Chi H and Sun L (2017) Neutrophil Extracellular Traps of

Cynoglossus semilaevis:

Production Characteristics and

Antibacterial Effect.

Front. Immunol. 8:290.

doi: 10.3389/fimmu.2017.00290

\section{Neutrophil Extracellular Traps of Cynoglossus semilaevis: Production Characteristics and Antibacterial Effect}

\author{
Ming-li Zhao ${ }^{1,2,3}$, Heng Chi' and Li Sun ${ }^{1 *}$ \\ ${ }^{1}$ Key Laboratory of Experimental Marine Biology, Institute of Oceanology, Chinese Academy of Sciences, Qingdao, China, \\ ${ }^{2}$ Laboratory for Marine Biology and Biotechnology, Qingdao National Laboratory for Marine Science and Technology, \\ Qingdao, China, ${ }^{3}$ University of Chinese Academy of Sciences, Beijing, China
}

Neutrophil extracellular traps (NETs) are structures released by neutrophils as a cellular immune defense against microbial invasion. The process of NETs generation, netosis (NETosis), can take place via either a suicidal mechanism, during which the NETsreleasing cells became dead, or a "live" mechanism, during which the NETs-releasing cells remain vital. NETosis has been studied intensively in mammals in recent years, but very little is known about the NETosis in fish. In this study, we examined NETosis in tongue sole (Cynoglossus semilaevis), a species of teleost with important economic values. We found that following stimulation with phorbol 12-myristate 13-acetate (PMA) and three common fish bacterial pathogens, abundant NETs structures were released by neutrophils that were most likely in a live state. The released NETs captured, but did not kill, the bacterial pathogens; however, the replication of extracellular, but not intracellular, pathogens was inhibited by NETs to significant extents. Reactive oxygen species (ROS), nitric oxide (NO), and myeloperoxidase (MPO) production were observed to be enhanced in NETosing neutrophils, and blocking the production of these factors by inhibitors significantly decreased NETs production induced by PMA and all three bacteria. Taken together, these results indicate for the first time that in teleost there exists a non-cell death pathway of NETosis that produces NETs with antibacterial effects in a ROS-, NO-, and MPO-dependent manner.

Keywords: neutrophil extracellular trap, NETosis, Cynoglossus semilaevis, antibacterial, innate immune defense

\section{INTRODUCTION}

Neutrophils are professional phagocytes that serve as the first line of defense against invading pathogens, thus playing a pivotal role in innate immune defense (1). Neutrophils kill microorganisms by phagocytosis and oxidative burst. In 2004, Brinkmann and colleagues reported NETosis, a new cell death pathway in human neutrophils that was distinct from apoptosis and necrosis and relied on a structure called neutrophil extracellular traps (NETs) $(2,3)$. NETs are web-like structures composed of extracellular DNA, histones, and antimicrobial proteolytic enzymes in the granules of neutrophils, such as neutrophil elastase and myeloperoxidase (MPO) (4). NETs have been reported to capture and 
immobilize bacteria; however, there is much controversy about whether NETs can directly kill bacteria (5).

In mammals, NETs are released from neutrophils in response to a wide spectrum of pro- and anti-inflammatory stimuli, such as phorbol 12-myristate 13-acetate (PMA), lipopolysaccharides, bacteria, fungi, viruses, and parasites (6). NETs were detected in mammals like mice (7), humans, rabbit (3), and dogs (8), as well as in chicken and marine animals $(9,10)$. However, reports from different laboratories often vary with respect to the timing and effectiveness of NETs production in response to different stimuli, which suggests that there exist more than one mechanism of NETs formation (11). Evidences have indicated that the formation of NETs requires the generation of reactive oxygen species (ROS) and nitric oxide (NO) (12-14). In addition, MPO, one of the most abundant proteins in neutrophils, is also a constituent of NETs (3, $15)$, and it has been reported that neutrophils from patients who lack the ability to produce MPO fail to produce NETs (16).

Compared to NETs studies in mammalian models, studies of NETs in fish are few. Although NETs-like structures have been observed in teleost species including turbot, fathead minnows, carp, and zebrafish (17-20), the underlying mechanism regulating NETosis and the functionality of NETs in fish are essentially unknown. Tongue sole (Cynoglossus semilaevis) is a flatfish with important economic values in China. In this study, we investigated the characteristics of NETs production by tongue sole neutrophils, with an emphasis on the effect of ROS, NO, and MPO. We also examined the antimicrobial effect of NETs against common fish bacterial pathogens.

\section{MATERIALS AND METHODS}

\section{Ethics}

Experiments involving live animals were conducted in accordance with the "Regulations for the Administration of Affairs Concerning Experimental Animals" promulgated by the State Science and Technology Commission of Shandong Province. The study was approved by the Ethics Committee of Institute of Oceanology, Chinese Academy of Sciences.

\section{Neutrophil Isolation}

Clinically healthy tongue sole (average $250 \mathrm{~g}$ ) were purchased from a local fish farm. Isolation of neutrophils was performed as reported previously $(17,21,22)$ with modifications as follows. Head kidney was aseptically collected from tongue sole and placed into a $50 \mathrm{ml}$ test tube containing $30 \mathrm{ml}$ of Hank's balanced salt solution with $\mathrm{Ca}^{2+}$ and $\mathrm{Mg}^{2+}$ but without phenol red (HBSS) (Mediatech-CellGro, AK, USA). The tissue was processed by being passed through a $100 \mu \mathrm{m}$ nylon Falcon cell strainer (BD Falcon, Lexington, KY, USA). The cells were isolated using 51\% percoll (GE Healthcare, Uppsala, Sweden), with the buffy coat being removed. The remaining red blood cell/granulocyte pellet was collected, and the red blood cells were separated using a specific gravity of $61 \%$ percoll. The granulocytes/macrophages were collected and pooled. The cells were washed twice in HBSS and seeded into $25 \mathrm{~cm}^{3}$ polystyrene cell culture flasks (Costar, Tewksbury, MA, USA) containing L15 medium (HyClone,
Logan, UT, USA) supplemented with $2 \%$ fetal bovine serum (HyClone, Logan, UT, USA) and cultured at $22^{\circ} \mathrm{C}$ with $5 \% \mathrm{CO}_{2}$ for overnight. The non-adherent neutrophil-like cells were harvested, and a portion of the cells were used for total cell count, and cytochemical staining as reported previously (17). As shown in Figure S1 in Supplementary Material, most of the prepared cells were neutrophils.

\section{Microscopy}

The inducers of NETosis used in this study were PMA and three fish bacterial pathogens. PMA was used because it is known to be a very effective inducer of NETosis in mammalian models (2), and therefore served in this study as a positive control for the three bacteria pathogens. Microscopic observation of NETs was performed as reported previously (17) with modifications. Briefly, the fish bacterial pathogens Pseudomonas fluorescens, Vibrio harveyi, and Edwardsiella tarda (23-25) were cultured in Luria-Bertani broth (LB) medium at $28^{\circ} \mathrm{C}$ to an $\mathrm{OD}_{600}$ of 0.8 ; the cells were collected by centrifugation and washed with PBS. Neutrophils $\left(\sim 10^{6}\right)$ were seeded onto a glass coverslip that had already been treated with $0.001 \%$ polylysine (Sigma, St. Louis, MO, USA) and placed in a 12-well cell culture plate. The cells were allowed to settle for $2 \mathrm{~h}$ and then treated with PMA $\left(1 \mu \mathrm{g} \mathrm{ml}^{-1}\right)$ (Sigma, St. Louis, MO, USA), $P$. fluorescens $\left(1 \times 10^{6} \mathrm{CFU}\right), V$. harveyi $\left(1 \times 10^{6} \mathrm{CFU}\right)$, or E. tarda $\left(1 \times 10^{6} \mathrm{CFU}\right)$ at $22^{\circ} \mathrm{C}$ for $2 \mathrm{~h}$. The control cells were left untreated. For fluorescent microscopy, Sytox Green was added to the cells, and after incubation for $5 \mathrm{~min}$, the cells were washed three times with PBS. Then the cells were fixed with $4 \%$ paraformaldehyde (Sigma, St. Louis, MO, USA) for 25 min and stained with 4',6-diamidino-2-phenylindole (DAPI) according to the instructions of the manufacturer (Bioss, Beijing, China). Scanning electron microscopy (SEM) was performed as reported (10).

\section{Survival of NETs-Trapped Bacteria}

The survival of NETs-entrapped bacteria was examined as reported previously (17). Briefly, bacterial cells were cultured in $\mathrm{LB}$ medium to an $\mathrm{OD}_{600}$ of 0.8 and harvested by centrifugation. The bacterial cells were washed with PBS for three times and resuspended in PBS. Neutrophils $\left(2 \times 10^{5}\right.$ cells/well in a $200 \mu \mathrm{l}$ volume) were seeded in 96-well cell culture plates and allowed to adhere for $60 \mathrm{~min}$ at $22^{\circ} \mathrm{C}$. The cells were then stimulated with $1 \mu \mathrm{g} \mathrm{ml}^{-1}$ PMA for $2 \mathrm{~h}$ and centrifuged at $400 \mathrm{~g}$ for $5 \mathrm{~min}$, and $150 \mu \mathrm{l}$ of supernatant was discarded. Then, $50 \mu \mathrm{l}$ L15 medium containing or not containing $100 \mathrm{U} \mathrm{ml}^{-1}$ DNase I was added to the cells. The cells were maintained at $22^{\circ} \mathrm{C}$ for $20 \mathrm{~min}$, then cytochalasin D $\left(20 \mu \mathrm{g} \mathrm{ml}^{-1}\right)$ (Invitrogen, Carlsbad, CA, USA) and 2,000 CFU bacteria ( $P$. fluorescens, $V$. harveyi, or E. tarda) were added to the plates. The plates were centrifuged at $800 \mathrm{~g}$ for $10 \mathrm{~min}$ to allow intimate contact of the bacteria with NETs/ neutrophils. The plates were then incubated at $22^{\circ} \mathrm{C}$ for $2,4,6$, and $8 \mathrm{~h}$. After incubation, the content of each well (bacteria plus neutrophils and NETs) was taken out and serially diluted, and the dilutions were plated on LB agar plates. The plates were incubated at $28^{\circ} \mathrm{C}$ for $24 \mathrm{~h}$, and the colonies that emerged on the plates were counted. The genetic nature of the colonies was verified by PCR and sequence analysis of the PCR products. 


\section{Quantification of NETs}

To quantify NETs, the method of Parker et al. (11) was adopted. Briefly, neutrophils $\left(5 \times 10^{6}\right.$ cells/well in a $200 \mu$ l volume $)$ were suspended in HBSS (Mediatech-CellGro, USA) and seeded in a black 96-well plate (Cayman Chemical, Ann Arbor, MI, USA). The cells were treated with PMA $\left(1 \mu \mathrm{g} \mathrm{ml} \mathrm{m}^{-1}\right), P$. fluorescens $\left(1 \times 10^{6} \mathrm{CFU}\right)$, V. harveyi $\left(1 \times 10^{6} \mathrm{CFU}\right)$, or E. tarda $\left(1 \times 10^{6} \mathrm{CFU}\right)$ for $1,2,3$, or $4 \mathrm{~h}$. The control cells were untreated. After treatment, the membrane-impermeable DNA-binding dye, Sytox Green $(5 \mu \mathrm{M})$, was added to the cells, followed by incubation for $5 \mathrm{~min}$. Fluorescence was then quantified as relative fluorescence units (RFU) at $485 \mathrm{~nm}$ excitation and $530 \mathrm{~nm}$ emission using a fluorescence spectrophotometer (Infinite M1000, Tecan, Switzerland). For NETs inhibition assay, neutrophils were pre-incubated with the following inhibitors for $30 \mathrm{~min}$ at $22^{\circ} \mathrm{C}$ : $100 \mu \mathrm{M}$ ROS scavenger Trolox (Sigma, St. Louis, MO, USA), $1 \mathrm{mM}$ nitric oxide (NO) inhibitor N(G)-nitro-L-arginine methylester L-NAME (Sigma, St. Louis, MO, USA), or $100 \mu \mathrm{M}$ MPO inhibitor 4-aminobenzoic acid hydrazide (ABAH) (Calbiochem, San Diego, CA, USA). NETs production and measurements were then performed as above.

\section{Measurement of ROS, NO, and MPO}

To measure ROS and NO production, the methods described by Patel et al. and Lim et al. $(26,27)$ were adopted, respectively. Briefly, neutrophils were suspended in HBSS and seeded in a black 96 -well plate $\left(5 \times 10^{6}\right.$ cells/well $)$. The cells were incubated with $10 \mu \mathrm{M} 2^{\prime}, 7^{\prime}$-dichlorofluorescein diacetate (DCFH-DA) (Sigma, USA) at $22^{\circ} \mathrm{C}$ for $20 \mathrm{~min}$ for ROS quantification and with $5 \mu \mathrm{M} 4,5$-diaminofluorescein diacetate (DAF-2DA) (Sigma, USA) for NO quantification, respectively. The plates were centrifuged for $10 \mathrm{~min}$ at $400 \mathrm{~g}$, and the supernatant was replaced with fresh HBSS containing PMA $\left(1 \mu \mathrm{g} \mathrm{ml}^{-1}\right)$, P. fluorescens $\left(1 \times 10^{6} \mathrm{CFU}\right)$, V. harveyi $\left(1 \times 10^{6} \mathrm{CFU}\right)$, or E. tarda $\left(1 \times 10^{6} \mathrm{CFU}\right)$. The control cells were untreated. The plates were incubated at $22^{\circ} \mathrm{C}$ for 20,40 , 80,100 , and $120 \mathrm{~min}$. After incubation, ROS and $\mathrm{NO}$ were measured as RFU at $485 \mathrm{~nm}$ excitation and $525 \mathrm{~nm}$ emission and at $495 \mathrm{~nm}$ excitation and $515 \mathrm{~nm}$ emission, respectively, using a fluorescence spectrophotometer (Infinite M1000, Tecan, Switzerland).

Myeloperoxidase release was measured as reported previously (18). Briefly, neutrophils were suspended in HBSS and seeded in a 96-well plate $\left(5 \times 10^{6}\right.$ cells/well $)$. The cells were treated with PMA $\left(1 \mu \mathrm{g} \mathrm{ml}^{-1}\right), P$. fluorescens $\left(1 \times 10^{6} \mathrm{CFU}\right), V$. harveyi $\left(1 \times 10^{6} \mathrm{CFU}\right)$, or E. tarda $\left(1 \times 10^{6} \mathrm{CFU}\right)$. The control cells were untreated. The cells were incubated at $22^{\circ} \mathrm{C}$ for 60 and $120 \mathrm{~min}$, and $50 \mu \mathrm{l}$ of $3,3^{\prime}, 5,5^{\prime}$-tetramethylbenzidine hydrochloride (TMB) (Sigma, USA) was added to the cells, followed by immediately adding $50 \mu \mathrm{l}$ of hydrogen peroxide. The color change reaction was allowed to proceed for $3 \mathrm{~min}$, and then $50 \mu \mathrm{l} 2 \mathrm{M}$ sulfuric acid was added to stop the reaction. The plates were centrifuged

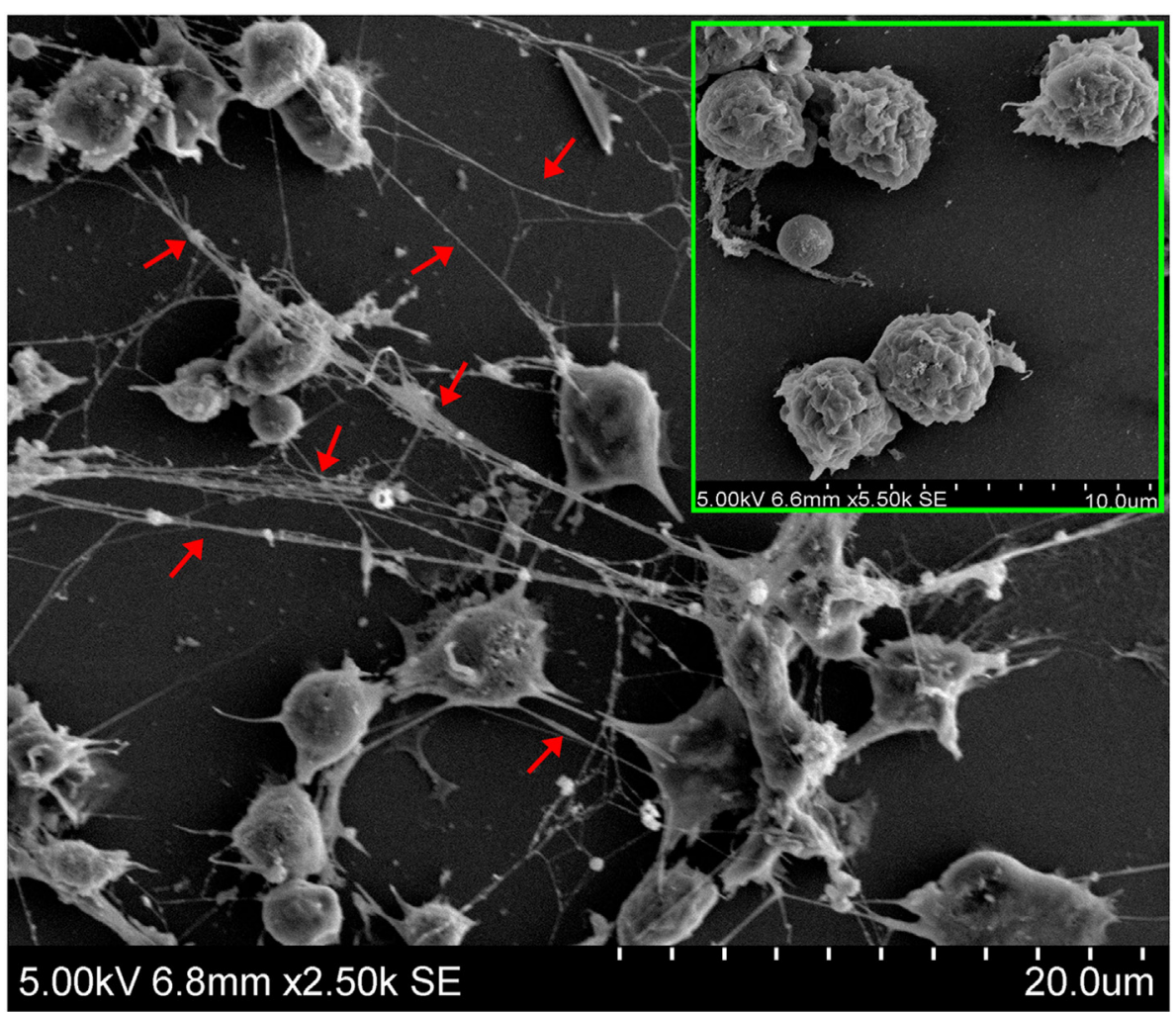

FIGURE 1 | Production of neutrophil extracellular traps (NETs) by neutrophils in response to phorbol 12-myristate 13-acetate (PMA) treatment. Tongue sole neutrophils were treated with or without (boxed image) PMA and observed with a scanning electron microscope. Arrows indicate NETs. 
at $400 \mathrm{~g}$ for $15 \mathrm{~min}$, and $200 \mu \mathrm{l}$ of the supernatant from each well was transferred to another plate and the optical density in each well was determined at $405 \mathrm{~nm}$.

\section{Statistical Analysis}

All experiments were performed three times, and statistical analyses were performed using analysis of variance with SPSS 17.0 software (SPSS Inc., Chicago, IL, USA). Statistical significance was determined with Student's $t$-test. In all cases, significance was defined as $P<0.05$.

\section{RESULTS}

\section{Production of NETs by Live Neutrophils}

Scanning electron microscopy showed that when tongue sole kidney neutrophils were treated with PMA, abundant NETs structures were produced, which contained long stretches of fibers dotted with spherical objects similar to the $25-50 \mathrm{~nm}$ globular protein domains observed in mammalian NETs (3) (Figure 1). To examine whether the NETs-producing neutrophils were alive, the cells were stained with Sytox Green, which
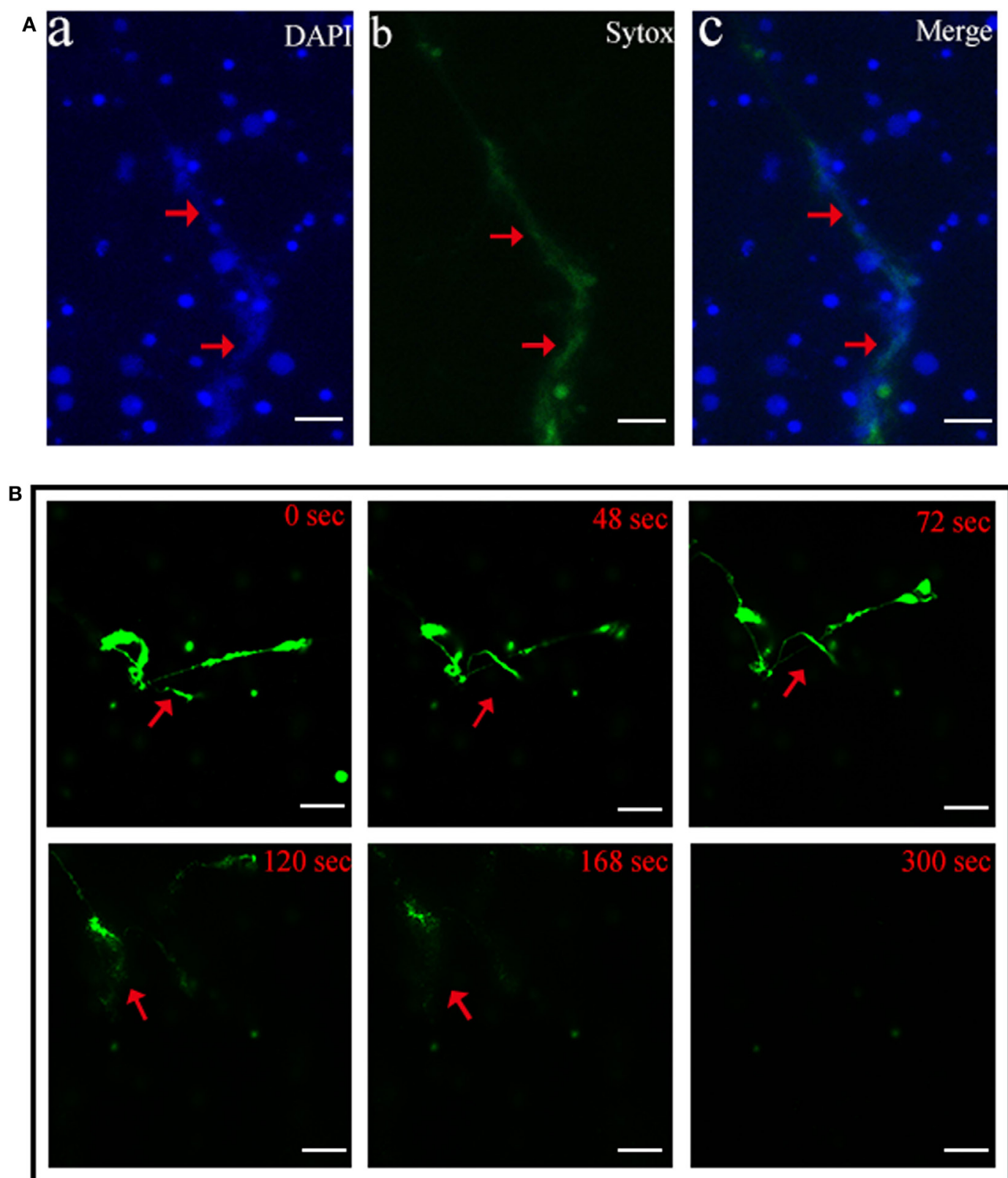

FIGURE 2 Production of neutrophil extracellular traps (NETs) by live neutrophils. (A) Tongue sole neutrophils were treated with phorbol 12-myristate 13-acetate (PMA) and stained with Sytox Green and DAPI. The cells were then observed with a fluorescence microscope. (B) PMA-treated neutrophils were stained with Sytox Green and incubated with DNase I for different times. The cells were observed as above. Arrows indicate NETs. Bar, 20 $\mu$ m. 
is impermeable to live cells, and DAPI after PMA treatment. The results indicated that DAPI was associated with both NETs and the cells, whereas Sytox Green was excluded from the cells (Figure 2A), suggesting that NETs were produced by live cells. Consistent with this observation, when PMA-induced NETs was incubated with DNase I, the NETs structure gradually disappeared as the incubation time increased (Figure 2B; Video S1 in Supplementary Material), suggesting that DNA was an essential component of NETs.

\section{NETosis Induced by Fish Pathogens}

The bacteria E. tarda, P. fluorescens, and V. harveyi are common pathogens to marine fish including tongue sole. To investigate their effects on NETosis, tongue sole neutrophils were incubated with each of these bacteria, and NETs production was subsequently determined microscopically. The results showed that SEM detected NETs formation in all groups of neutrophils treated with the bacteria, and that the produced NETs were able to trap the bacterial cells (Figure 3). Quantitative analysis revealed that bacteria-induced NETs production in a timedependent manner, with the amounts of NETs increasing from 1 to $4 \mathrm{~h}$ after bacterial treatment (Figure 4).

\section{NETs Entrapment on Bacterial Survival}

To examine the fate of the bacteria trapped by NETs, NETspositive neutrophils and NETs-negative neutrophils were incubated with E. tarda, P. fluorescens, and $V$. harveyi for 0,2 , 4,6 , or $8 \mathrm{~h}$, and viable bacteria were recovered at each time point. The results showed that for P. fluorescens and V. harveyi, the numbers of viable bacteria after 2 and $4 \mathrm{~h}$ incubation with NETs-positive neutrophils were comparable to those after incubation with NETs-negative neutrophils; however, after 6 and $8 \mathrm{~h}$ incubation, the bacterial recoveries from NETspositive neutrophils were significantly lower than those from NETs-negative neutrophils (Figures 5A,B). By contrast, for E. tarda, bacterial recoveries from NETs-positive neutrophils were similar to those from NETs-negative neutrophils at all time points (Figure 5C).

\section{ROS, NO, and MPO Production in Bacteria-Treated Neutrophils}

Reactive oxygen species analysis showed that in neutrophils treated with PMA, P. fluorescens, and $V$. harveyi, ROS levels increased with time, whereas in neutrophils treated with E. tarda, no apparent change in ROS was observed (Figure 6A). For NO and $\mathrm{MPO}$, their productions were enhanced significantly in a time-dependent fashion in neutrophils treated with all tested stimulants, i.e., PMA, E. tarda, P. fluorescens, and V. harveyi, with E. tarda being the strongest inducer among all bacteria for NO

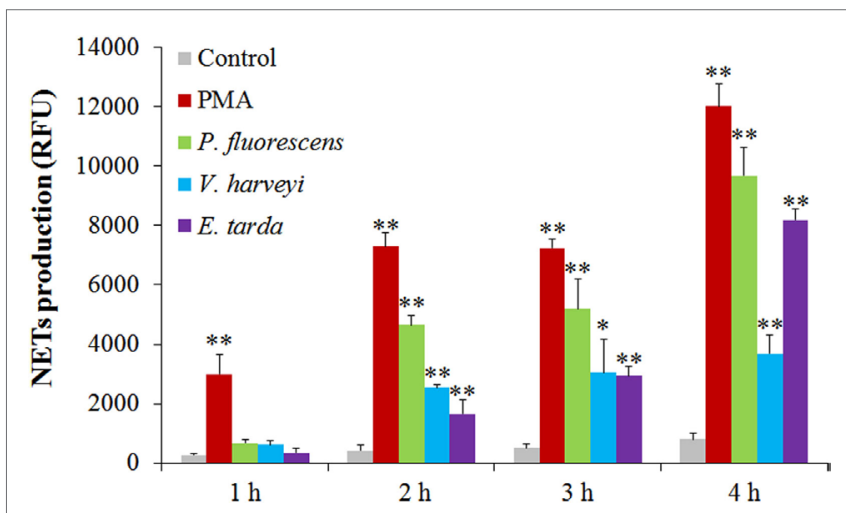

FIGURE 4 | Time-course production of neutrophil extracellular traps (NETs) by neutrophils in response to various treatments. Tongue sole neutrophils were treated with or without (control) phorbol 12-myristate 13-acetate (PMA), Pseudomonas fluorescens, Vibrio harveyi, and Edwardsiella tarda for various hours, and NETs production was determined. The experiment was performed three times, and the results are shown as means \pm SEM. ${ }^{\star \star} P<0.01 ;{ }^{\star} P<0.05$
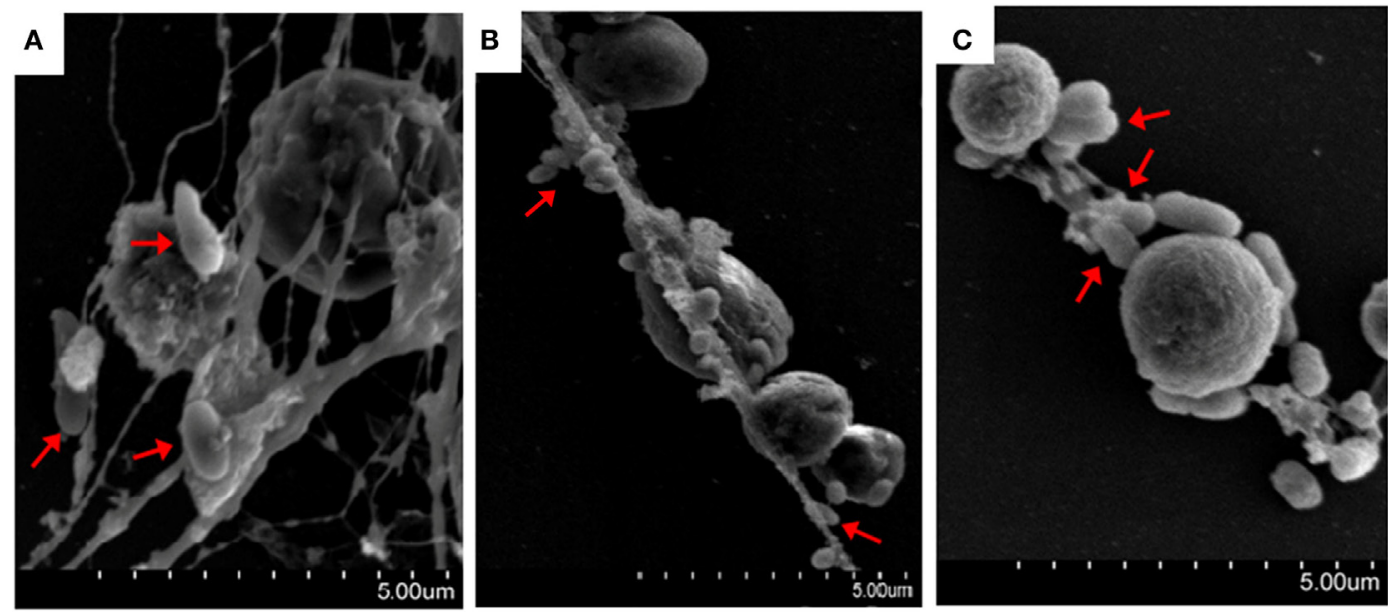

FIGURE 3 | Bacteria-induced production of neutrophil extracellular traps (NETs). Tongue sole neutrophils were treated with Pseudomonas fluorescens (A), Vibrio harveyi (B), and Edwardsiella tarda (C), and the cells were observed with a scanning electron microscope. Arrows indicate NETs-trapped bacteria. 

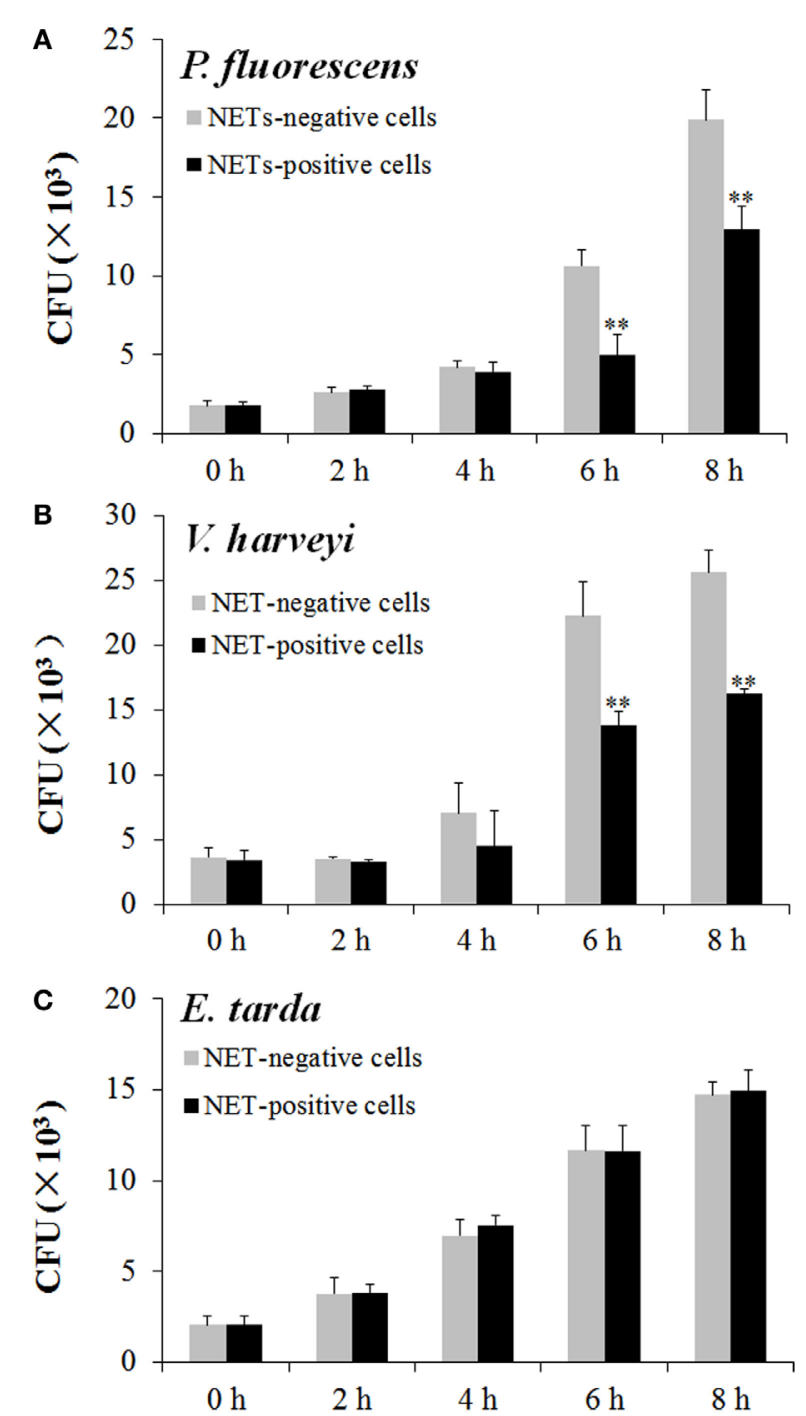

FIGURE 5 | Multiplication of neutrophil extracellular traps (NETs)trapped bacteria. Neutrophils were stimulated with phorbol 12-myristate 13-acetate for NETs production (NETs-positive cells), and a portion of the cells were then treated with DNase I to degrade NETs (NETs-negative cells). NETs-positive and NETs-negative cells were incubated with Pseudomonas fluorescens (A), Vibrio harveyi (B), and Edwardsiella tarda (C) for different hours, and bacterial numbers were determined by plate count. The experiment was performed three times, and the results are shown as means \pm SEM. ${ }^{\star \star} P<0.01$.

production (Figure 6B), and $V$. harveyi for MPO production (Figure 6C).

\section{Essentialness of ROS, NO, and MPO to Bacteria-Induced NETosis}

Given the above observation, we wondered whether ROS, NO, and MPO production was required for NETosis. To investigate this question, neutrophils were treated with PMA, E. tarda, $P$. fluorescens, and $V$. harveyi in the presence of the inhibitor against the production/accumulation of ROS, NO, or MPO, and

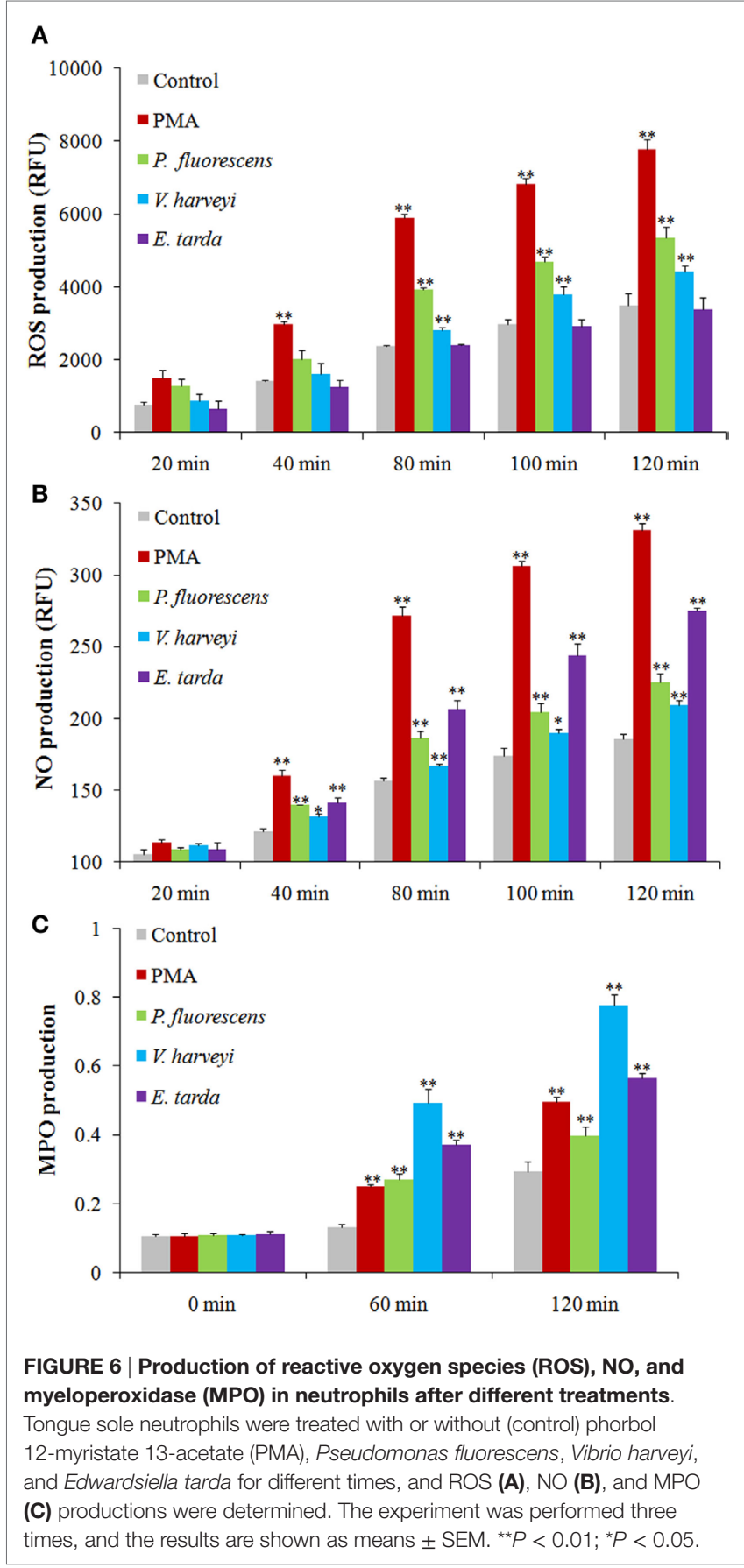

the amount of NETs produced by the cells was subsequently determined. The results showed that the presence of Trolox, L-NAME, and ABAH, which are inhibitors of ROS, NO, and $\mathrm{MPO}$, respectively, caused significant NETs reduction in all groups of neutrophils (Figure 7).

\section{DISCUSSION}

In mammals, NTEs are released by neutrophils in response to treatment with various stimulants including PMA, microorganisms, 


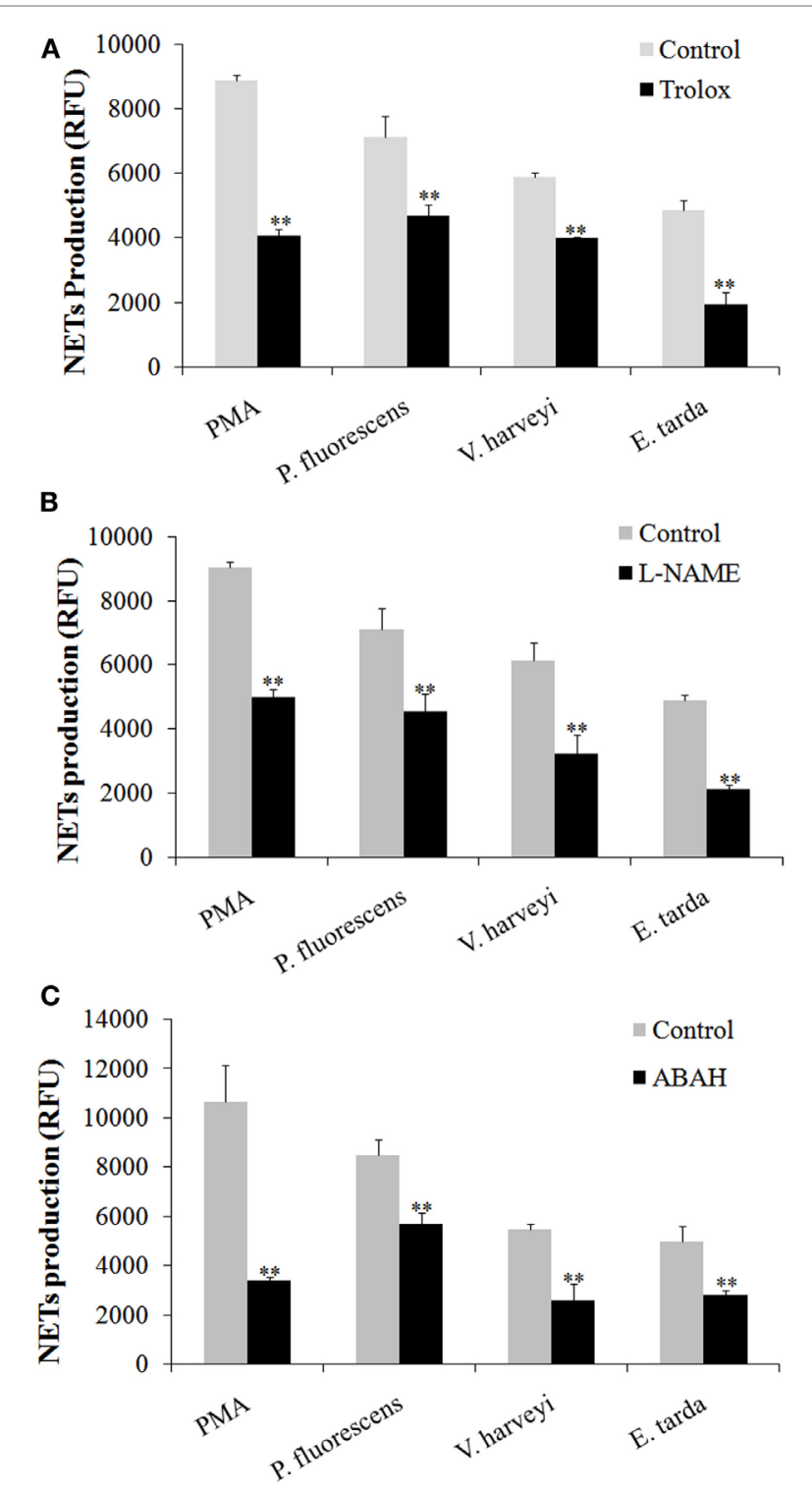

FIGURE 7 | Production of neutrophil extracellular traps (NETs) in response to various inhibitors. Tongue sole neutrophils were treated with phorbol 12-myristate 13-acetate (PMA), Edwardsiella tarda, Pseudomonas fluorescens, or Vibrio harveyi in the presence or absence (control) of Trolox (A), L-NAME (B), and ABAH (C), and NETs production was determined. The experiment was performed three times, and the results are shown as means \pm SEM. ${ }^{* \star} P<0.01$.

and cytokines $(2,3,28,29)$. In the current study, we found that after treatment with PMA, tongue sole neutrophils released abundant NETs structures. Brinkmann et al. have reported that in mammalian NETs, the diameter of single DNA stretches was 15-17 nm, and the DNA stretches were punctuated with globular protein domains ranging from 25 to $50 \mathrm{~nm}$ (3). In tongue sole NETs, we also observed smooth stretches of DNA fibers and intermittent globular complexes. Double-staining with the DNA specific fluorescent dyes Sytox Green and DAPI showed that while DAPI stained both the extracellular DNA in NETs and the nuclei of the cells, Sytox Green was associated only with the extracellular DNA in NETs, indicating that NETs were produced by living neutrophils. These results support the idea of vital NETosis, a process during which the cells release NETs while still maintaining their natural defense capacities as live cells (30).

Edwardsiella tarda, $V$. harveyi, and $P$. fluorescens are among the most common aquaculture pathogens with a wide host range including a large number of fish and shellfish. Of these bacteria, E. tarda is an intracellular pathogen known to be able to evade host immunity and replicate inside host phagocytes $(31,32)$. In this study, we found that all three bacteria triggered apparent NETosis in a time-dependent manner, and that the amounts of NETs formed varied after different bacterial treatments, suggesting that these pathogens differed in their NETs-inducing capacities. NETs have been reported to immobilize microbes since they were first discovered (3); however, the ability of NETs to kill microbes appears to differ under different conditions. For instance, Streptococcus pneumoniae and Streptococcus aureus were reported to be captured, but not killed, by mammalian NETs $(7,33,34)$, whereas Streptococcus flexneri and Candida albicans were directly killed by NETs $(3,15)$. In fish, our recent study demonstrated that turbot NETs were able to kill Escherichia coli but not $P$. fluorescens (17). In the case of tongue sole NETs, we observed entrapment of $P$. fluorescens, $V$. harveyi, and E. tarda by NETs. Plate count analysis showed that after NETs entrapment, the bacterial numbers of $V$. harveyi and $P$. fluorescens increased with time but at a rate significantly slower than that of the control bacteria, suggesting that these entrapped bacteria were still alive and capable of replication though in a significantly slower manner compared to the control bacteria. These results indicated that NETs immobilization did not kill $V$. harveyi and $P$. fluorescens but did interfere with the replication of these bacteria. In contrast to $V$. harveyi and $P$. fluorescens, entrapped E. tarda increased in number in a manner similar to that of the control cells, suggesting that NETs entrapment had no apparent impact on E. tarda as far as multiplication is concerned, which implies that $E$. tarda possesses a certain mechanism that enables the pathogen to resist the antimicrobial effect of NETs.

In mammals, evidences have shown that NETosis requires the generation of ROS by NADPH oxidase. Neutrophils from patients with mutations in NADPH oxidase and knockout mice that lacked functional NADPH oxidase failed to produce NETs in response to PMA $(12,13)$; NETs formation upon activation with bacteria was also impaired after pharmacological inhibition of respiratory burst with NADPH oxidase inhibitor (2). The underlying mechanism is that ROS is able to activate PAD4, which in turn mediates the citrullination of histone and results in chromatin decondensation, which is an essential of NETosis (5). Besides ROS, NO is another key player in NET formation both in human and mouse neutrophils $(26,27)$. It has shown that the NO mediates NETs release through free radical generation involving NADPH oxidase and MPO (27). In our study, we found that the presence of ROS and NO inhibitors significantly decreased NETosis triggered by $V$. harveyi and $P$. fluorescens. These results, together with the observation that both $V$. harveyi and $P$. fluorescens stimulated ROS and NO production in neutrophils, indicated that ROS and NO are important factors for 
NETosis induced by these pathogens. For E. tarda, we found that it enhanced NO production in neutrophils and, in line with this observation, its ability to produce NETs was significantly reduced by L-NAME, suggesting an essential role of NO in NETs formation. Although E. tarda did not promote ROS induction, it was affected significantly by ROS inhibitor in the capacity of NETosis. These results suggest that E. tarda-triggered NETosis required ROS, likely at a relatively low level, such as that constitutively expressed by the cells.

Myeloperoxidase is known to be a constituent of mammalian NETs $(3,15)$. MPO is released from azurophilic granule and translocates to the nucleus, where it binds to chromatin and promotes chromatin decondensation, whereby leading to NET release (4). It has been shown that a partial disorder of MPO production resulted in a reduction and delay of NETs formation, and that neutrophils completely deficient in MPO failed to produce NETs in response to PMA and C. albicans in humans (16). Parker et al. reported that in human neutrophils, MPO was required for NETosis triggered by PMA, but bacteria-induced NETosis was independent of MPO activity (11). In tongue sole neutrophils, we found that MPO production was enhanced by PMA as well as three bacterial pathogens, and that the presence of MPO inhibitor significantly reduced NETs production caused by PMA, E. tarda, $V$. harveyi, and P. fluorescens, indicating an essential role of MPO in NETosis triggered by these inducers. These observations suggest a possible difference in the mechanism of bacteria-induced NETosis between fish and human neutrophils.

In conclusion, we, in this study, demonstrated for the first time that (i) NETs were produced by live neutrophils of tongue sole after chemical and bacterial stimulation, which suggests the existence of a non-cell death pathway of NETosis in fish; (ii) the fish NETs were able to immobilize bacterial pathogens and inhibit the replication of $V$. harveyi and $P$. fluorescens but not the replication of the intracellular pathogen $E$. tarda, which suggests that evasion

\section{REFERENCES}

1. Nathan C. Neutrophils and immunity: challenges and opportunities. Nat Rev Immunol (2006) 6(3):173-82. doi:10.1038/nri1785

2. Fuchs TA, Abed U, Goosmann C, Hurwitz R, Schulze I, Wahn V, et al. Novel cell death program leads to neutrophil extracellular traps. J Cell Biol (2007) 176(2):231-41. doi:10.1083/jcb.200606027

3. Brinkmann V, Reichard U, Goosmann C, Fauler B, Uhlemann Y, Weiss DS, et al. Neutrophil extracellular traps kill bacteria. Science (2004) 303:1532-5. doi:10.1126/science. 1092385

4. Papayannopoulos V, Metzler KD, Hakkim A, Zychlinsky A. Neutrophil elastase and myeloperoxidase regulate the formation of neutrophil extracellular traps. J Cell Biol (2010) 191(3):677-91. doi:10.1083/jcb.201006052

5. Stephan A, Fabri M. The NET, the trap and the pathogen: neutrophil extracellular traps in cutaneous immunity. Exp Dermatol (2015) 24(3):161-6. doi:10.1111/exd.12599

6. von Kockritz-Blickwede M, Nizet V. Innate immunity turned inside-out: antimicrobial defense by phagocyte extracellular traps. J Mol Med (Berl) (2009) 87(8):775-83. doi:10.1007/s00109-009-0481-0

7. Beiter K, Wartha F, Albiger B, Normark S, Zychlinsky A, Henriques-Normark B. An endonuclease allows Streptococcus pneumoniae to escape from neutrophil extracellular traps. Curr Biol (2006) 16(4):401-7. doi:10.1016/j. cub.2006.01.056

8. Jeffery U, Kimura K, Gray R, Lueth P, Bellaire B, LeVine D. Dogs cast NETs too: canine neutrophil extracellular traps in health and immune-mediated of NETs-mediated immune response is probably a virulence strategy of E. tarda; and (iii) in both bacteria- and PMA-triggered NETosis, ROS, NO, and MPO play a significant role, suggesting a common fundamental NETs production process in tongue sole neutrophils. Taken together, these findings add new insights into the mechanism of NETosis and the functionality of NETs in fish.

\section{AUTHOR CONTRIBUTIONS}

LS conceived and designed the experiments; M-1Z and HC performed the experiments; $\mathrm{M}-\mathrm{lZ}$ and $\mathrm{HC}$ analyzed the data; $\mathrm{M}-\mathrm{lZ}$ and LS wrote the manuscript. All authors read and approved the final manuscript.

\section{FUNDING}

This work was supported by the grants from the National Natural Science Foundation of China (41576150 and 31330081), the Scientific and Technological Innovation Project and the AoShan Talents Program supported by Qingdao National Laboratory for Marine Science and Technology (No. 2015ASKJ02 and No. 2015ASTP), and the Taishan Scholar Program of Shandong Province.

\section{SUPPLEMENTARY MATERIAL}

The Supplementary Material for this article can be found online at http://journal.frontiersin.org/article/10.3389/fimmu.2017.00290/ full\#supplementary-material.

FIGURE S1 | Microscopic examination of tongue sole neutrophils. Neutrophils from tongue sole kidney were stained with potassium iodidepyronine $\mathrm{G}$ and observed with a microscope. The cells with brown granules were neutrophil-like cells, some of which are indicated by arrows. Bar $=10 \mu \mathrm{M}$.

hemolytic anemia. Vet Immunol Immunopathol (2015) 168(3-4):262-8. doi:10.1016/j.vetimm.2015.10.014

9. Chuammitri P, Ostojic J, Andreasen CB, Redmond SB, Lamont SJ, Palic D. Chicken heterophil extracellular traps (HETs): novel defense mechanism of chicken heterophils. Vet Immunol Immunopathol (2009) 129(1-2):126-31. doi:10.1016/j.vetimm.2008.12.013

10. Ng TH, Chang SH, Wu MH, Wang HC. Shrimp hemocytes release extracellular traps that kill bacteria. Dev Comp Immunol (2013) 41(4):644-51. doi:10.1016/j.dci.2013.06.014

11. Parker H, Dragunow M, Hampton MB, Kettle AJ, Winterbourn CC. Requirements for NADPH oxidase and myeloperoxidase in neutrophil extracellular trap formation differ depending on the stimulus. J Leukoc Biol (2012) 92(4):841-9. doi:10.1189/jlb.1211601

12. Bianchi M, Hakkim A, Brinkmann V, Siler U, Seger RA, Zychlinsky A, et al. Restoration of NET formation by gene therapy in CGD controls aspergillosis. Blood (2009) 114(13):2619-22. doi:10.1182/blood-2009-05-221606

13. Ermert D, Urban CF, Laube B, Goosmann C, Zychlinsky A, Brinkmann V. Mouse neutrophil extracellular traps in microbial infections. J Innate Immun (2009) 1(3):181-93. doi:10.1159/000205281

14. Lee C, Miura K, Liu X, Zweier JL. Biphasic regulation of leukocyte superoxide generation by nitric oxide and peroxynitrite. J Biol Chem (2000) 275(50):38965-72. doi:10.1074/jbc.M006341200

15. Urban CF, Reichard U, Brinkmann V, Zychlinsky A. Neutrophil extracellular traps capture and kill Candida albicans yeast and hyphal forms. Cell Microbiol (2006) 8(4):668-76. doi:10.1111/j.1462-5822.2005.00659.x 
16. Metzler KD, Fuchs TA, Nauseef WM, Reumaux D, Roesler J, Schulze I, et al. Myeloperoxidase is required for neutrophil extracellular trap formation: implications for innate immunity. Blood (2010) 117(3):953-9. doi:10.1182/ blood-2010-06-290171

17. Chi H, Sun L. Neutrophils of Scophthalmus maximus produce extracellular traps that capture bacteria and inhibit bacterial infection. Dev Comp Immunol (2016) 56:7-12. doi:10.1016/j.dci.2015.11.005

18. Palic D, Ostojic J, Andreasen CB, Roth JA. Fish cast NETs: neutrophil extracellular traps are released from fish neutrophils. Dev Comp Immunol (2007) 31(8):805-16. doi:10.1016/j.dci.2006.11.010

19. Brogden G, von Kockritz-Blickwede M, Adamek M, Reuner F, Jung-Schroers V, Naim HY, et al. Beta-glucan protects neutrophil extracellular traps against degradation by Aeromonas hydrophila in carp (Cyprinus carpio). Fish Shellfish Immunol (2012) 33(4):1060-4. doi:10.1016/j. fsi.2012.08.009

20. Palic D, Andreasen CB, Ostojic J, Tell RM, Roth JA. Zebrafish (Danio rerio) whole kidney assays to measure neutrophil extracellular trap release and degranulation of primary granules. J Immunol Methods (2007) 319(1-2):8797. doi:10.1016/j.jim.2006.11.003

21. Katzenback BA, Belosevic M. Isolation and functional characterization of neutrophil-like cells, from goldfish (Carassius auratus L.) kidney. Dev Comp Immunol (2009) 33(4):601-11. doi:10.1016/j.dci.2008.10.011

22. Palic D, Andreasen CB, Frank DE, Menzel BW, Roth JA. Gradient separation and cytochemical characterisation of neutrophils from kidney of fathead minnow (Pimephales promelas Rafinesque, 1820). Fish Shellfish Immunol (2005) 18(3):263-7. doi:10.1016/j.fsi.2004.07.003

23. Zhang $\mathrm{WW}, \mathrm{Hu} \mathrm{YH}$, Wang $\mathrm{HL}$, Sun L. Identification and characterization of a virulence-associated protease from a pathogenic Pseudomonas fluorescens strain. Vet Microbiol (2009) 139(1-2):183-8. doi:10.1016/j. vetmic.2009.04.026

24. Yu LP, Hu YH, Sun BG, Sun L. Immunological study of the outer membrane proteins of Vibrio harveyi: insights that link immunoprotectivity to interference with bacterial infection. Fish Shellfish Immunol (2013) 35(4):1293-300. doi:10.1016/j.fsi.2013.07.043

25. Li MF, Sun L, Li J. Edwardsiella tarda evades serum killing by preventing complement activation via the alternative pathway. Fish Shellfish Immunol (2015) 43(2):325-9. doi:10.1016/j.fsi.2014.12.037

26. Patel S, Kumar S, Jyoti A, Srinag BS, Keshari RS, Saluja R, et al. Nitric oxide donors release extracellular traps from human neutrophils by augmenting free radical generation. Nitric Oxide (2010) 22(3):226-34. doi:10.1016/j. niox.2010.01.001

27. Lim MB, Kuiper JW, Katchky A, Goldberg H, Glogauer M. Rac2 is required for the formation of neutrophil extracellular traps. J Leukoc Biol (2011) 90(4):771-6. doi:10.1189/jlb.1010549

28. Clark SR, Ma AC, Tavener SA, McDonald B, Goodarzi Z, Kelly MM, et al. Platelet TLR4 activates neutrophil extracellular traps to ensnare bacteria in septic blood. Nat Med (2007) 13(4):463-9. doi:10.1038/nm1565

29. Yousefi S, Mihalache C, Kozlowski E, Schmid I, Simon HU. Viable neutrophils release mitochondrial DNA to form neutrophil extracellular traps. Cell Death Differ (2009) 16(11):1438-44. doi:10.1038/cdd.2009.96

30. Yipp BG, Kubes P. NETosis: how vital is it? Blood (2013) 122(16):2784. doi:10.1182/blood-2013-04-457671

31. Rao PSS, Lim TM, Leung KY. Opsonized virulent Edwardsiella tarda strains are able to adhere to and survive and replicate within fish phagocytes but fail to stimulate reactive oxygen intermediates. Infect Immun (2001) 69(9):5689-97. doi:10.1128/IAI.69.9.5689-5697.2001

32. Zhou Z-J, Sun L. Edwardsiella tarda-induced inhibition of apoptosis: a strategy for intracellular survival. Front Cell Infect Microbiol (2016) 6:76. doi:10.3389/ fcimb.2016.00076

33. Wartha F, Beiter K, Albiger B, Fernebro J, Zychlinsky A, Normark S, et al. Capsule and D-alanylated lipoteichoic acids protect Streptococcus pneumoniae against neutrophil extracellular traps. Cell Microbiol (2007) 9(5):1162-71. doi:10.1111/j.1462-5822.2006.00857.x

34. Menegazzi R, Decleva E, Dri P. Killing by neutrophil extracellular traps: fact or folklore? Blood (2012) 119(5):1214-6. doi:10.1182/blood-2011-07364604

Conflict of Interest Statement: The authors declare that the research was conducted in the absence of any commercial or financial relationships that could be construed as a potential conflict of interest.

Copyright (C) 2017 Zhao, Chi and Sun. This is an open-access article distributed under the terms of the Creative Commons Attribution License (CC BY). The use, distribution or reproduction in other forums is permitted, provided the original author(s) or licensor are credited and that the original publication in this journal is cited, in accordance with accepted academic practice. No use, distribution or reproduction is permitted which does not comply with these terms. 